\title{
Exploration of Rural Biogas Construction and Economic Benefit
}

\author{
Wu Yihui, Li Dongmei \\ School of management, Sichuan Agricultural Uniersity, Chengdu, Sichuan 611130
}

Keywords: biogas construction; three rural issues; environmental benefits; economic benefits

\begin{abstract}
In recent years, a lot of biogas projects in rural areas of our country started or have been put into use. As an alternative resource, biogas not only effectively curbed the deterioration of the environmental pollution in the countryside, but also was of great significance in meeting the demand for energy for farmers in our country. At the same time, the economic benefits of rural farmers were raised, but this technique was used. During the promotion stage, we encountered such problems as construction funding gap, immature technology and so on. This paper expounds the above problems and puts forward relevant handling methods.
\end{abstract}

\section{Introduction}

China is a big agricultural country, most of which are closely related to agriculture, and the proportion of rural population is also the largest. The energy sources in the area are relatively lack, the source of daily life energy is mainly burning straw, and the shortage of energy has made the rural economic development lagging behind. In recent years, under the guidance of national preferential policies and the call of "green home and ecological agriculture" in rural areas, the agricultural production of the multi industrial chain, such as "pig one marsh one rice", "pig a marsh one vegetable", "pig a marsh one cane", "pig a marsh one tea" and "one flower of pig a marsh", is being put forth under the call of the country. The new form saves resources, protects the ecosystem, and realizes the close combination of biogas technology and aquaculture, planting industry and so on. The popularization of biogas has not only weakened the reduction in the air quality from its application, but also adapted to the energy requirements of the farmers in the aspects of living cooking and electric lights in reality, and solved the energy crisis in the countryside, especially the biological activity of the biogas fertilizer for agricultural production and the development of the new countryside. Great significance[1].

\section{Current Situation of Rural Biogas Construction}

The main sources of rural pollution in China are the following aspects: the end of the production and life in rural areas, and the unpurification of the daily life. This kind of behavior causes the pollution of natural resources such as water, land, atmosphere, biologic chain and food chain. With the deepening of the reform of the industry, the breeding of domestic animals and poultry has been deepened, but at the same time, the malpractice of the pollution of the feces is also formed, which is also an important reason for the environmental pollution in the countryside. For some big agricultural provinces, it is obvious that the proportion of agriculture is the largest in gross domestic product, and the proportion of livestock breeding in total agricultural output is more than $1 / 3$, and the huge amount of feces becomes the most serious source and source of pollution. Security poses a great threat. Second, the excessive use of pesticides and chemical fertilizers in agricultural development is not only uneconomical, but also causes serious environmental damage, which pollutes the working environment and the natural environment. It is embodied in the following aspects: first, chemical fertilizer enters natural rivers, lakes, reservoirs, and river ponds, so that the water is polluted, and the water area may affect the biological chain by eutrophication. The second is that the improper use of chemical fertilizer leads to the decrease of soil activity, and the negative effect of the harmful chemical components in the chemical fertilizer on the agricultural environment, resulting in the decrease of the quality of the crops. The harm of pesticide lies in its pervading in the 
environment, causing pollution to the water, soil, gas and various kinds of agricultural products in the natural environment and causing the ultimate harm to the human body through biological links. In addition, some highly toxic pesticides in the process of destroying pests also destroy the beneficial insects and the beneficial birds, and destroy the ecological balance. If the resistance of the pests is increasing, the amount of the pesticide will inevitably increase, and the pollution damage of the agricultural environment will inevitably aggravate, and the later fruit of its deterioration will be unthinkable. Because of the combination of the randomness and universality of the rural production and life, the pollution area is large, it involves many departments, it is easy to be hidden, the monitoring difficulty is high, and it is difficult to be analyzed from the numerical analysis. This makes this type of pollution a culprit of the rural ecological environment deterioration. If it is not effectively controlled and the prospect is worried, it is not only related to agriculture. The real interests of the village will affect social harmony, economic level and people's living standard in the long run[2].

The biogas project in rural areas has shown remarkable results in controlling natural pollution. First, the promotion of biogas projects, from the raw materials used, can make use of domestic waste, feces and waste water to produce biogas and fertilizer in the pool, thus reducing the overflow of pollutants to the atmosphere, water and viruses, gradually mature and scientific in the treatment of waste and feces, and because of the unique biogas chemistry. The effect, the bacteria and larvae lack of survival conditions, the elimination of a large number of mosquitoes and flies, limited the number of mosquitoes, the prevalence of infectious diseases, the lack of odor, the air is also a lot of fresh, good for the health of human and livestock. Second, the use of biogas instead of traditional burning straw will greatly reduce the air pollution caused by smog emission. Third, the substitution of biogas will reduce the excessive dependence of agriculture on chemical fertilizers and pesticides, and thus protect the atmosphere, natural water, soil and crop environment from pollution. Fourth, biogas, as a feasible measure, is very helpful to achieve the goal of agricultural environmentfriendly production. The resources of biogas, with its very clean characteristics, play a self-evident role in daily cooking. At the same time, its by-products, such as slag and liquid, are very high in organic matter content, regardless of their N, P, K content or various kinds of amino acids and organic enzymes. For crop growth, the fertility is obvious, and this nature is natural. Instead of traditional fertilizer, it not only treated the waste, but also contained the amount of chemical fertilizer from the source, especially in the fields of rice, fungus, fruit and vegetable. It not only can improve the ability of lodging resistance to crops, but also greatly reduce the amount of chemical fertilizer and pesticide, reduce the incidence of disease and insect pests, from the economic cost, It is also very economical and practical, and has improved the safety of agricultural products, and has truly realized green pollution-free agricultural products. Biogas and development not only protect the environment and natural resources, but also produce positive environmental benefits on this basis. Using this green energy, it has fundamentally replaced the dependence on trees and indirectly protected the rare forest resources in China from this angle. Due to the recycling of waste liquid waste as fertilizer, it can grow economic trees on the barren hills, increase the income and inhibit soil erosion, purify the water source, optimize the local microclimate, and improve the health of the villagers. So we can get the following conclusion: the promotion of biogas in rural areas not only reduces the destruction of pesticide and chemical fertilizer to the environment, but also improves the economic benefit, make the rural agriculture achieve sustainable development, and can contribute to the improvement of rural face: because the whole process has no disease and insect breeding, especially clean and tidy[3].

\section{The Corresponding Economic Value of Rural Biogas Industry}

The relevant research shows that once the capacity of the biogas digester reaches 8 cubic meters, only with the proper technology and 400 cubic meters of biogas production capacity, 2 tons of coal can be saved, electricity can be saved to 200 degrees, and the cost of reducing the traditional energy is about 1500 yuan. The by-products such as biogas fertilizer are equivalent to 60 kilograms of potassium sulphate and 50 male. Calcium superphosphate and 20 kilograms of potassium chloride, 
the crop yield increased to $6 \%-25 \%$, and the liquid was improved as pig feed in the biogas pool. The time of the column was nearly one month ahead, and the cost of each pig was nearly 50 yuan. It can be said that the introduction of biogas production into traditional agricultural production and life will lead to economic growth in geometric multiples. In the future, only a few pigs' feces will be fermented in the pool. If appropriate, the biogas production capacity of the biogas pool will be satisfied. With the production of the biogas digester, the biogas will replace the traditional energy and realize the function of lighting and cooking. Biogas has obvious effect on saving coal consumption. Studies have shown that the cost of using biogas can be reduced by more than $60 \%$ compared with conventional coal.

\section{The Maladies in the Construction of Rural Biogas in China}

China's vast rural areas are in underdeveloped or underdeveloped areas. A rural family needs to invest about 200 yuan to build a biogas pool. It needs to invest 1500 yuan for follow-up construction, such as kitchen renovation, toilet reform, livestock ring transformation, and so on. At present, the state does not invest much in the project, and only about 1000 of the funds are supported by the pool. The rest can only be borne by the villagers themselves. In the countryside, especially in the poor village, the situation is more serious, and the confidence of the villagers to carry out the biogas project is eliminated in a certain range, and the corresponding promotion work has been stagnant[4].

In the process of implementing biogas construction in rural areas, only some achievements have been made in household use. Although the number of biogas pools in some rural areas has been greatly improved, most of the biogas pool construction standards are different, and the use efficiency is not high. In many areas, the original method is used to build the biogas pool, the fermentation process is backward, and the input and output ratio is too large. The second is that it is not used frequently after production and there is no economic benefit to talk about. At present, the construction of biogas pool in China is mainly based on site processing and installation. It is limited by terrain and site, without the support of relevant industry standards and standardized equipment. The project has long period of implementation, not easy to maintain, and lack of related quality assurance system. The management of materials entering and construction management lacks professional management, resulting in low construction efficiency. The above actual situation has caused the relatively backward development of the industry, and needs to be changed from labor intensive to knowledge intensive.

The scale of the construction of most rural biogas pools in China is only on the scale of one mouth per household, and the scale of various rural household biogas pools is small enough to supply only a few pig feed, put pig manure into the biogas pool to produce biogas, supply family electricity and catering, waste waste liquid to fertilize the farmland, and less industrial biogas projects. . The characteristics of biogas, such as natural gas, coal and oil, are characterized by their reproducibility, which are doomed to pay attention to their high cost performance and promote the process of industrialization[5].

Because of the lack of knowledge, many rural population is afraid of developing biogas technology because of lack of technology. Because of the lack of access to knowledge, the awareness of these groups is only in lighting, cooking, environmental protection and protection of natural resources and the realization of sustainable development.

\section{Measures to Improve the Construction of Biogas in the future}

From its own, the importance and urgency of developing the biogas industry, as well as the difficulties encountered in the process of development, as well as the various difficulties encountered in the process of development, are taken into account by the national and provincial and county and County township levels, as much as possible from the national capital to develop various kinds of funds for the development of biogas projects, and the introduction of funds to prevent excessive cost and capital input. The burden of rural residents is too heavy, which affects 
the enthusiasm of biogas construction.

The backward technology level is the biggest fetter in the implementation of rural biogas projects in China. In the field of government, we should strengthen the popularization of biogas engineering, increase the strength of training and assessment from the perspective of managers and operators, attract relevant design and construction maintenance personnel with good treatment, and use technical personnel to teach local farmers about biogas related technology, build a scientific and technological station and deepen the knowledge and technology of biogas. Dissemination and promotion to meet the needs of the continuous development of rural biogas, improve the quality of biogas pools, deepen the product function of biogas technology, and meet the demand for biogas projects in rural areas. In addition to actively promoting the capital investment, the government related science and technology administrative departments should make efforts to contact the advanced units of relevant technical industries, introduce advanced technology, combine universities and scientific research units, combine local practice, and actively explore the core technologies of Biogas Development under the new situation. Strong team construction and feasibility study to form industrial development. If we have the scale, we can build related R \& D bases and promote exchanges to the local area and even the whole country. In order to solve the problems in the development, we should gather all the experts to carry out the "brain storm" and discuss the improvement plan. This can ensure that the construction of biogas project has always been developing in a positive direction and has a great advance for the progress of China's rural biogas industry.

In order to build up a follow-up service system, this process must be combined with the needs of the villagers, consider the future development of biogas, comprehensively adjust the technical input, pay attention to the comprehensive development in the function, improve the efficiency and improve the utilization level of the biogas project, and arrange or teach professional and technical personnel to solve all kinds of appearance. Or problems that may arise, and remove the worries from the mind for the villagers. The government should give full play to the corresponding functions, such as encouraging the association to lead, individual work, and various organizational forms of cooperation, from the policy to ensure that the relevant interests are in place. Let rural biogas projects make use of their natural advantages to contribute to the sustainable development of agriculture in the new era. promote the development of rural biogas industry towards industrialization. In recent years, the rural migrant workers in the remote areas of our country have increased dramatically. Many families have been unattended for years and have been stagnant in livestock breeding. In the rural areas, all households with biogas pools can not be realized in the rural areas. As the biogas pools appear in a small scale, they are not industrialized in the rural areas, even in the middle of the country. The scale has not yet been formed. In practice, some sustainable fermentation projects can be managed commercialized, and biogas will be produced for the surrounding villagers to be used by the surrounding villagers. If a stable large scale biogas power generation project is built, the charge can be realized, which not only facilitates the villagers but also promotes the development of the industrial economy.

\section{Conclusion}

The level of development of rural construction in China is changing rapidly, and the corresponding demand for resources has also developed rapidly. However, with the rapid development of the rural economy, the excessive reliance on and environment of the traditional energy is destroyed. This kind of contradiction is deepening. As a good substitute for resources and an important intermediate link for sustainable development of energy, the clean and pollution-free energy of biogas is believed to be suitable for the future rural economy. Building a greater contribution.

\section{References}

[1] Haryanto A, Cahyani D, Triyono S, et al. Economic Benefit and Greenhouse Gas Emission 
Reduction Potential of A Family-Scale Cowdung Anaerobic Biogas Digester[J]. 2017, 6(1):29.

[2] Yasar A, Nazir S, Tabinda A B, et al. Socio-economic, health and agriculture benefits of rural household biogas plants in energy scarce developing countries: A case study from Pakistan [J]. Renewable Energy, 2017, 108:19-25.

[3] Abbas T, Ali G, Adil S A, et al. Economic analysis of biogas adoption technology by rural farmers: The case of Faisalabad district in Pakistan [J]. Renewable Energy, 2017, 107:431-439.

[4] Qin H Y. Effects of Application of Biogas Slurry on Yield and Economic Benefits of Maize[J]. Tillage \& Cultivation, 2016.

[5] Jin-Huai L I, Liang L, Gan F D, et al. Effect of Biogas Manures Application on Cayenne Pepper Quality and Economic Benefit [J]. China Biogas, 2016.

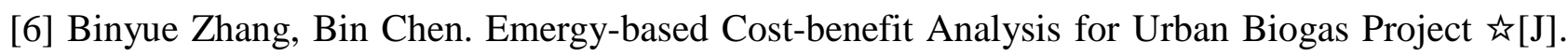
Energy Procedia, 2016, 88:119-125. 